\title{
Avoidant Learning Ability in Free Flying Housefly (Aldrichina grahami) by Electric Shock
}

\author{
JIANG Ping ${ }^{1,2}$, ZHOU Dong-ming ${ }^{1}$, MA Yuan-ye (, * $^{\text {* }}$ \\ (1. Laboratory of Primate Neuroscience Research and Key Laboratory of Animal Models and Human Disease Mechanisms, \\ Kunming Institute of Zoology, the Chinese Academy of Sciences, Kunming 650223, China; \\ 2. Graduate University of the Chinese Academy of Sciences, Beijing 100049, China)
}

\begin{abstract}
Previous studies have confirmed that both honeybee and Drosophila are capable of learning and memory. This study aimed to investigate whether the house fly (Aldrichina grahami), with strong instincts to adapt their living environment, have the learning ability to associate odor stimulus to avoid electric shock in free flying state using a device developed by the authors. The result showed the learning ability of A. grahami at the electric shock voltages of $5 \mathrm{~V}, 25 \mathrm{~V}$ and $45 \mathrm{~V}$ AC. When $60 \mathrm{~V}$ was used, the flies were frequently injured. Our results indicate that $A$. grahami is a good model to study the neural mechanism of learning and memory. The paradigm in this study has some advantages that can be used in future studies of free insects.
\end{abstract}

Key words: Aldrichina grahami; Free flying state; Avoidant learning; Electro-shock; Voltage threshold

\section{巨尾阿丽蝇在自由状态下的电击回避学习能力}

\author{
蒋 苹 1,2 , 周东明 ${ }^{1}$, 马原野 $1^{*}$
}

(1. 中国科学院昆明动物研究所 灵长类认知实验室, 云南 昆明 650223；2. 中国科学院研究生院, 北京 100049)

摘要: 研究证实: 蜜蜂和果蝇具有良好的学习记忆能力。利用自主改良的研究装置对另一种具有强大生存本 能的双翅目昆虫一巨巨尾阿丽蝇(Aldrichina grahami)在自由状态下电击回避学习能力进行研究。结果表明, 巨尾阿 丽蝇具有良好的学习记忆能力, 因为当刺激电压范围为 $5 \mathrm{~V}$ 到 $45 \mathrm{~V}$ 时, 观察到巨尾阿丽蝇有显著的回避电刺激行为, 而当电压达到 $60 \mathrm{~V}$ 时会受到明显伤害。由此推测, 巨尾阿丽蝇适合作为神经系统研究的动物模型。该实验所采用 的实验范例较以往有所改进, 适合作为自由状态下研究昆虫的工具。

关键词: 巨尾阿丽蝇; 自由状态; 回避学习; 电刺激; 电压阈值

中图分类号: Q969.453.2; Q965; Q967 文献标识码：A 文章编号：0254-5853-(2009)05-0515-05

Instincts and learning ability are two ways for animals to adapt their living environment. The former is developed during the processes of evolution while the latter is acquired during individual development. Instincts are important to the adaptation of animals that have short life cycles and forage independently of parental care. The learning ability, however, is relatively less important.

Recent studies have confirmed that learning ability is important to insects. It has been confirmed that the capability of learning in Drosophila (Quinn et al, 1974; Tully \& Quinn, 1985) and honeybees (Scheiner et al,
1999; Vergoz et al, 2007) is good to some extent. However, Drosophila feed on rotten fruit, which are comparatively rare in natural environment. Learning ability is therefore necessary for them to seek food and survive. Moreover, social insect honeybees also require learning ability to communicate for food resources and predator presence among individuals.

In comparison to Drosophila and honeybee, the short life cycled house fly have stronger instincts to adapt their living environment, such as robust propagation and great olfactory, to enable them to locate food efficiently. This experiment aims to investigate

Received date: 2009-05-11; Accepted date: 2009-06-08

收稿日期: 2009-05-11; 接受日期：2009-06-08

基金项目: 云南省社会发展科技计划（2008CA012-5）

“通讯作者（Corresponding author）, E-mail: yuanma0716@vip.sina.com

第一作者（First author）,E-mail: jphappy001@163.com 
whether the housefly (Aldrichina grahami), which have such strong instincts, also have learning ability.

In behavior research, appetitive and aversive conditioning are two models used to test animal learning and memory ability. In the current study we used electric shock as aversive stimulus to mimic the passive avoidance learning paradigm (Jarvik \& Kopp, 1967) and investigate the behavior of the flies in it.

\section{Materials and Methods}

\subsection{Insects}

Adult Dipteran house fly Aldrichina grahami were captured by a fly catcher from an outdoor environment, and the body length of chosen fly is between $9.0 \mathrm{~mm}$ and $13.0 \mathrm{~mm}$ in our experiment. Flies were reared under the conditions of $12: 12 \mathrm{~h}$ light: dark cycle at approximately $25^{\circ} \mathrm{C}$, $50 \%$ relative humidity and fed on $50 \%$ sucrose solution and water ad libitum for 3 days. The life cycle of this species is approximately 10 days under the condition of $25^{\circ} \mathrm{C}$ from eggs to adults (Fan et al, 1997).

\subsection{Behavior observations, apparatus and materials}

Prior to experiment commencement, the flies were deprived of food for 22 hours to enhance their motivation to search for food. And they couldn't eat any thing either during the whole experiment which was conducted within testing devices, developed by the authors. Each fly was tested individually during the experiment within a plastic box of volume $36 \mathrm{~L}(48 \mathrm{~cm} \times 30 \mathrm{~cm} \times 25 \mathrm{~cm})$ as seen in Fig. 1. The box contained two glass petri dishes (diameter $\sim 7.0 \mathrm{~cm}$ ) with one filled with water, and the other with a mixture of muscalure and bait. This mixture mainly produced the odors of the pheromones cis-9-tricosene, cis-9-heneicosene and fecal type. A 20\% sucrose solution was sprayed onto the mixture to enhance the attraction to food-deprived flies. A grid, of alternately connected stainless steel wire $(0.30 \mathrm{~mm}$ diameter, $2.4 \mathrm{~mm}$ apart), covered the glass petri dish of mixture. Flies were unable to access the mixture. Five levels of aversive stimuli were used at the voltages of 0 , $5,25,45$ and $60 \mathrm{~V}, \mathrm{AC} 50 \mathrm{~Hz}$ (Dudai, 1977). The 0V group acted as the control group. A video camera, which was connected to a computer, was fixed on the box to record the behavior of the flies. Digital video analysis software was used to record behavior only when the fly was in proximity of the mixture petri dish. If a fly were to touch two neighboring electrodes (Fig. 1) they were shocked. Four devices enabled simultaneous testing.

\subsection{Data analysis}

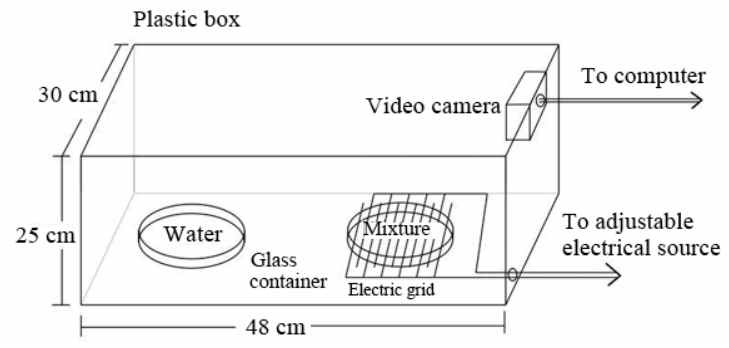

Fig. 1 A sketch of the experimental apparatus

During the trial, a fly landing on the grids and flying away was considered one avoidant learning trial and scored as 1. Each experiment lasted for 5 hours commencing from their first learning trial. The sum of the scores in each hour, and half hour was regarded as the behavior index of each fly.

Fly data was classified into five groups $(0,5,25,45$ and $60 \mathrm{~V} \mathrm{AC)} \mathrm{according} \mathrm{to} \mathrm{the} \mathrm{different} \mathrm{electro-shock}$ strength. A General Linear Model (Repeated Measures ANOVA) (Qiu et al, 2007) was implemented in SPSS 13.0 to analyze the effects of time, group, and time $\times$ group interaction of this dependent data. The Least Significant Difference (LSD) method (Qiu et al, 2007) was then used to make multiple comparisons between groups and time periods.

Due to large changes in the behavior between the first and second hour a delta value $(\Delta)$ was defined, which showed the difference and allowed comparison of the decreasing trend. A Mann-Whitney test was then used to evaluate the differences of deltas between groups (Roussel et al, 2009). Differences were considered significant when $P \leqslant 0.05$. Data for flies that did not touch the grids or that died within the 5 hours was discarded.

\section{Results}

In the $60 \mathrm{~V}$ trials, flies that touched the grids were frequently unable to fly again or died immediately. This determined the strength of $60 \mathrm{~V}$ was too strong, and the data was subsequently removed from analysis.

\subsection{Analysis by half hour in the first two hours}

2.1.1 Time effects As the largest changes occurred between the first two hours, we analyzed the time effects on learning scores per half hour. It was hypothesized that if the flies have learning ability, the learning scores of the experiment groups would decrease significantly in later time periods.

Time effect was found to be significant by integrated analysis of the four groups $(P<0.001)$. Time 
effect was also significant in each experiment group with the exception of the control group $(P=0.185, P<0.001$, $P<0.001$, and $P=0.001$ in $0,5,25$, and $45 \mathrm{~V}$ groups respectively).

Multiple comparisons within each group showed that there was no significant decrease of scores in comparison to the first unit of the control group (LSD: $0.5-1$ hour vs. $0-0.5$ hour $P=0.229,1-1.5$ hour vs. $0-0.5$ hour $P=0.088$, and $1.5-2$ hour vs. $0-0.5$ hour $P=0.440$ ) (Fig. 2), but there was a significant decrease from the second unit in each experiment group (Fig. 2).

These findings reveal that flies can learn to associate with the odor to avoid electric shock. Furthermore, as there was no significant decrease in the control group, the possibility that fly landing times decreased over time due to no food awarding in the experimental groups could be excluded. If no food awarding was the reason for the decreasing trend in the experimental groups, the scores in the control group would also be expected to decrease significantly.

The average scores per half hour in the first two hours are shown in Fig. 2 and Tab. 1. Tab. 1 also shows the $P$ value of time effects for each group.

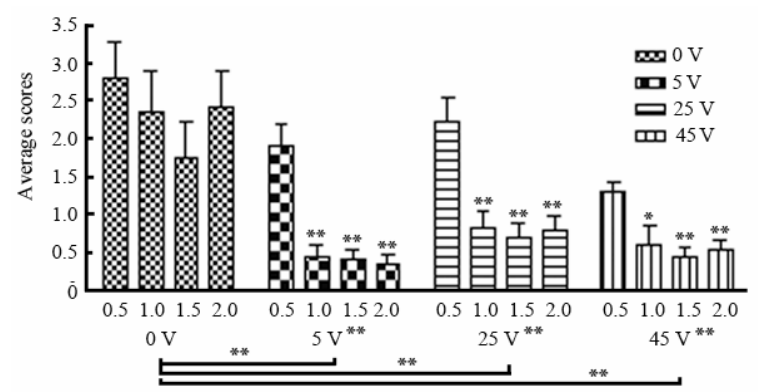

Fig. 2 Average scores per half hour in the first two hours in each group

Data were expressed as mean $\pm S E$. *: $P \leqslant 0.05, * *: P \leqslant 0.01$

Tab. 1 Average scores $\pm S E$ per half hour in the first two hours with associated $P$ values

\begin{tabular}{lcccccc}
\hline \multirow{2}{*}{ Groups } & Fly number & \multicolumn{4}{c}{ Average scores $\pm S E$ in each half hour } & Time effect in each \\
\cline { 2 - 5 } & $n$ & $0-0.5$ hour & $0.5-1$ hour & $1-1.5$ hour & $1.5-2$ hour & group $(P$ value $)$ \\
\hline $0 \mathrm{~V}$ & 25 & $2.8 \pm 0.5$ & $2.4 \pm 0.5$ & $1.8 \pm 0.5$ & $2.4 \pm 0.5$ & 0.185 \\
$5 \mathrm{~V}$ & 23 & $1.9 \pm 0.3$ & $0.4 \pm 0.2$ & $0.4 \pm 0.2$ & $0.3 \pm 0.1$ & $<0.001$ \\
$25 \mathrm{~V}$ & 36 & $2.2 \pm 0.3$ & $0.8 \pm 0.2$ & $0.7 \pm 0.2$ & $0.8 \pm 0.2$ & $<0.001$ \\
$45 \mathrm{~V}$ & 23 & $1.3 \pm 0.1$ & $0.6 \pm 0.2$ & $0.4 \pm 0.1$ & $0.5 \pm 0.1$ & $=0.001$ \\
\hline
\end{tabular}

2.1.2 Group effects and time $\times$ group interaction In order to better explain the effect of the stimulus on the learning ability of the flies, we analyzed the group effects. The results showed that the group effect were significant $(P<0.001)$. The scores of each experiment group were found to be significantly different from the control group (LSD: $5 \mathrm{~V}$ vs. $0 \mathrm{~V} P<0.001,25 \mathrm{~V}$ vs. $0 \mathrm{~V} P<0.001,45 \mathrm{~V}$ vs. $0 \mathrm{~V} \quad P<0.001)$. However, there was no significant difference among experimental groups (LSD: $25 \mathrm{~V}$ vs. 5 $\mathrm{V} P=0.295,45 \mathrm{~V}$ vs. $5 \mathrm{~V} P=0.884,45 \mathrm{~V}$ vs. $25 \mathrm{~V} P=0.227)$. This indicates that the shocking intensity of $5 \mathrm{~V}, 25 \mathrm{~V}$ and $45 \mathrm{~V}$ had almost the same effect on the flies' learning ability.

The interaction effect of time and group was also non significant $(P=0.137)$, this indicates that the effects of time and voltage were independent factors influencing the behavior of the housefly.

\subsection{Analysis by hours}

Further more, in order to test the longer learning and memory ability of the flies, we analyzed the data by the unit of one hour. The analysis results were similar to the half hour analysis. The overall time effect was significant $(P<0.001)$ among the five time-periods when the group data was combined. The time effect was also significant in each individual experimental group, except the control group $(P=0.092, P=0.010, P=0.003$, and $P=0.011$ in $0,5,25$ and $45 \mathrm{~V}$ group respectively). In LSD analysis, there was no significant difference among the 5 hours in control group (LSD: 2nd hour vs. 1st hour $P=0.236$, 3 rd hour vs. 1 st hour $P=0.063$, 4 th hour vs. 1 st hour $P=0.068$ and 5 th hour vs. 1 st hour $P=0.094$ ) (Fig. 3).

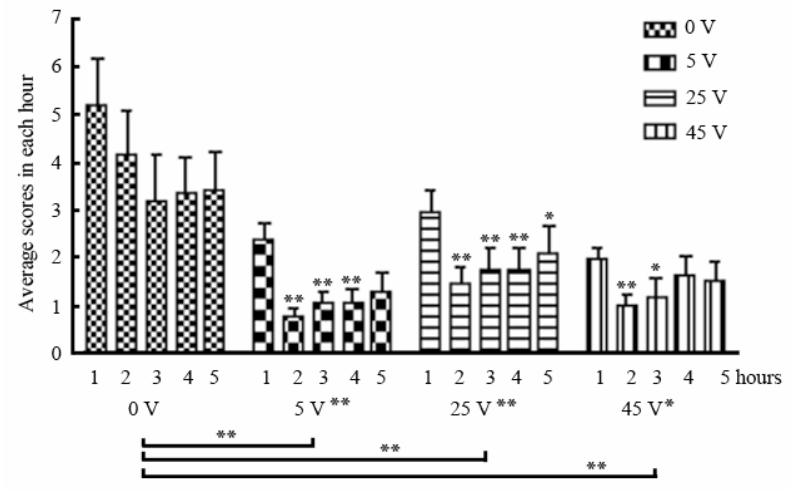

Fig. 3 Average scores of five hours' data in each group Data were expressed as mean \pm SEM. *: $P \leqslant 0.05,{ }^{*}: P \leqslant 0.01$. 
The group effect was found to be significant among the four groups $\left(F_{3,103}=6.085, P=0.001\right)$. LSD analysis showed the differences were significant between the $0 \mathrm{~V}$ group and the other groups (LSD: $5 \mathrm{~V}$ vs. $0 \mathrm{~V} P<0.001$, $25 \mathrm{~V}$ vs. $0 \mathrm{~V} P=0.003$, $45 \mathrm{~V}$ vs. $0 \mathrm{~V} P=0.001$ ). However, there was no significant difference between two of the three experiment groups (LSD: $5 \mathrm{~V}$ vs. $25 \mathrm{~V} P=0.260,5 \mathrm{~V}$ vs. $45 \mathrm{~V} P=0.803,25 \mathrm{~V}$ vs. $45 \mathrm{~V} P=0.394)$. The effects of the time $\times$ group interaction was not significant either $(P=0.468)$. Average scores in each hour of the four groups are showed in Fig. 3 and Tab. 2, with Tab. 2 also illustrating the $P$ value of the time effect for each group.

Tab. 2 Average scores $\pm S E$ over 5 hours with associated $P$ value of time effect

\begin{tabular}{|c|c|c|c|c|c|c|c|}
\hline \multirow[t]{2}{*}{ Groups } & \multirow{2}{*}{$\begin{array}{c}\text { Fly number } \\
n \\
\end{array}$} & \multicolumn{5}{|c|}{ Average scores $\pm S E M$ in each hour } & \multirow{2}{*}{$\begin{array}{l}\text { Time effect in each } \\
\text { group ( } P \text { value })\end{array}$} \\
\hline & & 1st hour & 2nd hour & 3 rd hour & 4th hour & 5th hour & \\
\hline $0 \mathrm{~V}$ & 25 & $5.2 \pm 0.9$ & $4.2 \pm 0.9$ & $3.2 \pm 1.0$ & $3.3 \pm 0.8$ & $3.4 \pm 0.8$ & 0.092 \\
\hline $5 \mathrm{~V}$ & 23 & $2.3 \pm 0.4$ & $0.7 \pm 0.2$ & $1.0 \pm 0.3$ & $1.0 \pm 0.3$ & $1.3 \pm 0.4$ & 0.010 \\
\hline $25 \mathrm{~V}$ & 36 & $2.9 \pm 0.5$ & $1.4 \pm 0.4$ & $1.8 \pm 0.5$ & $1.8 \pm 0.5$ & $2.1 \pm 0.5$ & 0.003 \\
\hline $45 \mathrm{~V}$ & 23 & $2.0 \pm 0.2$ & $1.0 \pm 0.2$ & $1.2 \pm 0.4$ & $1.7 \pm 0.4$ & $1.5 \pm 0.4$ & 0.011 \\
\hline
\end{tabular}

There were some differences between the hour analysis and the half hour analysis results that the data significantly rebounded in later time periods in the $5 \mathrm{~V}$ and $45 \mathrm{~V}$ groups. In the $5 \mathrm{~V}$ group, this was observed in the last hour (LSD: 5 th hour vs. 1 st hour $P=0.066$ ) (Fig. $3)$. While in the $45 \mathrm{~V}$ group, the scores rebounded in the last two hours (LSD: 4 th hour vs. 1 st hour $P=0.259$ and 5th hour vs. 1st hour $P=0.226$ ) (Fig. 3).

\subsection{Delta $(\Delta)$ value}

This data showed that the highest and lowest values in each group were always in the first and the second hour respectively. We therefore analyzed the delta $(\Delta)$ value to compare the decreasing trend. Our hypothesis was that the larger the $\Delta$ value, the better learning ability of the flies.

The mean values $\pm S E$ of delta $(\Delta)$ in each group were $1.0 \pm 0.9,1.6 \pm 0.3,1.5 \pm 0.3$ and $1.0 \pm 0.2$ (Fig. 4). There was no significant difference among the four groups, neither between groups. The decreasing trend was highest in $5 \mathrm{~V}$ group, while the trend was lowest in $45 \mathrm{~V}$ group.

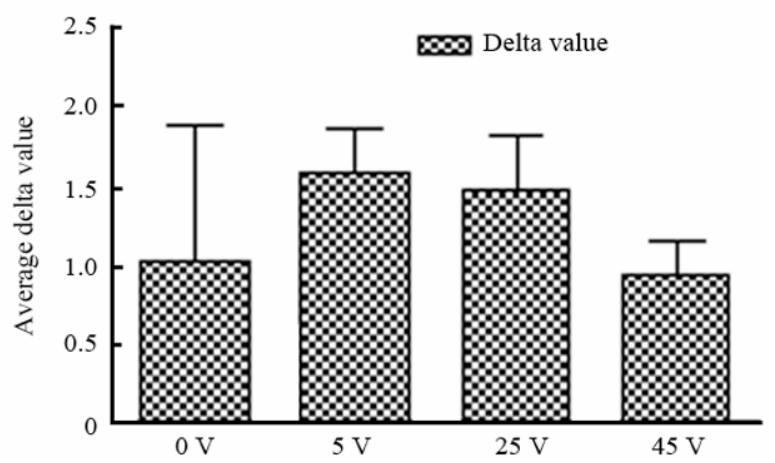

Fig. 4 The average values of delta $(\Delta)$ in each group Data were expressed as mean $\pm S E$

\section{Discussion}

The current study shows that the housefly (Aldrichina grahami) has learning ability even at low voltage strength $(5 \mathrm{~V})$, and that this ability emerges within the second half of the first hour. One possible reason for this is that the housefly (A. grahami) living environment is complex and involves many life-threatening factors. So learning ability is important for them to avoid threats.

Furthermore, the score in the second hour of the $5 \mathrm{~V}$ group was the lowest among all the groups, and the decreasing trend was more dominant than the other two voltage groups. It is possible that the voltage strength of $5 \mathrm{~V}$ is more appropriate for the flies to learn than the other groups, while the $45 \mathrm{~V}$ is so strong that their neural system might be affected and their behavior became abnormal as seen in the increasing shock times resulting in the dominant rebound in the last two hours. The least rebound in the $25 \mathrm{~V}$ group suggested that this voltage is suitable for the middle-time learning and memory of the flies. The rebound may also be explained by an increase in their need for food, habituating to the voltage, or not remembering the stimulus. The desire for food and searching instinct may also explain why the scores, except in the first hour of the experiment, would not go down to zero.

When interpreting the behavior exhibited, there are some advantages to our experiment. For example the flies need not be anesthetized or restrained before training, there is little interference from people or environment for independent recording, and they are in a free flying state throughout the experiment. Our experiment is therefore relatively reliable.

Other factors may also influence the fly behavior, 
such as ongoing exposure to the odor throughout the experiment and unfixed intervals between trials. An indicator in the device, to confirm the shocking behavior, would produce more precise results.

Despite finding that such housefly exhibit learning ability, there are still some areas of investigation needed in the future. For example, whether the mushroom body and the neural transmitters of catecholamines dopamine and octopamine (Schwaerzel et al, 2003) of A. grahami are as important during the formation of learning and memories as in Drosophila (Schwaerzel et al, 2003; Davis, 2005).

In summary, this study supports two major

\section{References:}

Davis RL. 2005. Olfactory memory formation in Drosophila: from molecular to systems neuroscience [J]. Annu Rev Neurosci, 28: 275-302.

Dudai Y. 1977. Properties of learning and memory in Drosophila melanogaster [J]. J Comp Physiol A, 114(1): 69-89.

Fan ZD, Chen ZZ, Fang JM, Zheng SS, Tao ZL. 1997. Fauna Sinica Insecta : Vol. 6, Diptera: Calliphoridae [M]. Beijing: Science Press, 102-103.

Jarvik ME, Kopp R. 1967. An improved one-trial passive avoidance learning situation [J]. Psychol Rep, 21(1): 221-224.

Qiu H, Jin GQ, Jin RF, Zhao WK. 2007. Analysis of variance of repeated data measured by water maze with SPSS [J]. J Chn Integr Med: Zhong Xi Yi Jie He Xue Bao, 5(1): 101-105. [In Chinese]

Quinn WG, Harris WA, Benzer S. 1974. Conditioned Behavior in Drosophila melanogaster [J]. Proc Natl Acad Sci USA, 71(3): 708-712. conclusions. First, adult Dipteran housefly A. grahami have learning ability in our experiment paradigm. The avoidance learning ability is necessary for them to live. So it should be considered that this species exhibit intelligence to some extent. Second, A. grahami are so sensitive to stimulus that they can learn under low voltage ( $\geqslant 5 \mathrm{~V} A C)$. In our experiment, the lower threshold of the voltage strength for the flies' learning is $5 \mathrm{~V}$, while the upper threshold is $45 \mathrm{~V}$.

Acknowledgement: Thank you to Scott Groom for his efforts in correcting and improving the English writing of this paper.

Roussel E, Carcaud J, Sandoz JC, Giurfa M. 2009. Reappraising social insect behavior through aversive responsiveness and learning $[\mathrm{J}]$. PLOS ONE, 4(1): e4197.

Scheiner R, Erber J, Page RE. 1999. Tactile learning and the individual evaluation of the reward in honey bees (Apis mellifera L.) [J]. $J$ Comp Physiol A, 185(1): 1-10.

Schwaerzel M, Monastirioti M, Scholz H, Grelin FF, Birman S, Heisenberg M. 2003. Dopamine and octopamine differentiate between aversive and appetitive olfactory memories in Drosophila [J]. J Neurosci, 23(33): 10495-10502.

Tully T, Quinn WG. 1985. Classical conditioning and retention in normal and mutant Drosophila melanogaster [J]. J Comp Physiol A, 157(2): 263-277.

Vergoz V, Roussel E, Sandoz JC, Giurfa M. 2007. Aversive learning in honeybees revealed by the olfactory conditioning of the sting extension reflex [J]. PLOS ONE, 2(3): e288. 